\title{
Economic burden of neural tube defects and impact of prevention with folic acid: a literature review
}

\author{
Yunni Yi • Marion Lindemann • Antje Colligs • \\ Claire Snowball
}

Received: 23 March 2011 / Accepted: 4 May 2011 / Published online: 19 May 2011

(C) The Author(s) 2011. This article is published with open access at Springerlink.com

\begin{abstract}
Neural tube defects (NTDs) are the second most common group of serious birth defects. Although folic acid has been shown to reduce effectively the risk of NTDs and measures have been taken to increase the awareness, knowledge, and consumption of folic acid, the full potential of folic acid to reduce the risk of NTDs has not been realized in most countries. To understand the economic burden of NTDs and the economic impact of preventing NTDs with folic acid, a systematic review was performed on relevant studies. A total of 14 cost of illness studies and 10 economic evaluations on prevention of NTDs with folic acid were identified. Consistent findings were reported across all of the cost of illness studies. The lifetime direct medical cost for patients with NTDs is significant, with the majority of cost being for inpatient care, for treatment at initial diagnosis in childhood, and for comorbidities in adult life. The lifetime indirect cost for patients with spina bifida is even greater due to increased morbidity and premature mortality. Caregiver time costs are also significant. The results from the economic evaluations demonstrate that folic acid fortification in food and preconception folic acid consumption are cost-effective ways to reduce the incidence and prevalence of NTDs. This review highlights the significant cost burden that NTDs pose to healthcare systems, various healthcare payers, and society and concludes that the benefits of prevention of NTDs with folic acid far outweigh the cost. Further intervention with
\end{abstract}

Y. Yi $(\bowtie) \cdot$ C. Snowball

Mapi Values,

Bollington, Cheshire SK10 5JB, UK

e-mail: Yunni.Yi@mapivalues.com

M. Lindemann $\cdot$ A. Colligs

Bayer Schering Pharma AG,

Berlin, Germany folic acid is justified in countries where the full potential of folic acid to reduce the risk of NTDs has not been realized.

Keywords Neural tube defects · Spina bifida $\cdot$ Economic burden $\cdot$ Cost $\cdot$ Folic acid $\cdot$ Prevention

\section{Introduction}

Neural tube defects (NTDs) are the second most common group of serious birth defects. NTDs result from failure of the neural tube to close properly, approximately 28 days postconception. Typically, this occurs before the woman knows that she is pregnant $[7,38]$. Despite the identified association between the achievement of adequate folate level at time of conception and a risk reduction of NTDs, NTDs have a complex and imperfectly understood aetiology in which both genetic and environmental factors appear to be involved [7].

Two of the most common NTDs are spina bifida and anencephaly. Spina bifida results from failure of fusion of the posterior (caudal) neural tube, whereas anencephaly results from failure of fusion of the anterior (cranial) neural tube. Anencephaly is fatal; many children with anencephaly are stillborn or die shortly after birth. Fifty percent have a life expectancy of between a few minutes and 1 day, and $25 \%$ only live up to 10 days [29]. Children with spina bifida have a high probability of lifelong physical and mental handicap, and only a minority of these children are able to function independently as adults [41]. Due to advances in medical technology, the life expectancy of patients with spina bifida is rising annually, with $85 \%$ to $90 \%$ of children born with the disease surviving into adulthood [46].

Patients with NTDs regularly have problems related to hydrocephalus, neurogenic bladder, kidney involvement, 
the orthopaedic complications, and the psychosocial consequences. These complications can cause severe disability, which add significant burden to patients with NTDs and their families.

Each year, 300,000 to 400,000 infants worldwide are born with spina bifida and anencephaly [16]. Approximately 4,500 pregnancies every year in Europe result in a baby or foetus affected by an NTD, and in the USA, 2,500 live births are affected by NTDs each year [51]. In China, 100,000 infants are born annually with NTDs [7].

Treatment for spina bifida includes surgery, medication, and physiotherapy. Surgery to close the newborn's spinal opening is generally performed within $24 \mathrm{~h}$ after birth to minimize the risk of infection and to preserve existing function in the spinal cord. However, regular monitoring, ongoing therapy, and medical and/or surgical treatments are often necessary to prevent and manage complications throughout the individual's life. Although many advances have been made in the treatment of spina bifida, resulting in increased life expectancy and improved quality of life for individuals with the disease, no treatment exists that will completely eliminate the serious disability or premature mortality associated with it. For these reasons, reducing the risk of NTDs is an important goal.

Most cases of anencephaly and spina bifida can be detected through prenatal screening methods such as second trimester maternal serum alpha-fetoprotein screening and foetal ultrasound scanning [33]. However, parents face great distress at the diagnosis of an NTD, confronting either the grief of a termination or stillbirth or the extensive emotional and financial challenges of caring for a child with NTD [32].

Folic acid has been shown to reduce effectively the risk of NTDs in 1990s [5], and this is supported by the evidence from recent systematic reviews on folic acid for the prevention of NTDs in both high- and low-income countries $[6,52]$. Although not all cases of NTDs can be prevented by increasing the intake of folic acid due to a 'floor effect' [26], studies have suggested that $50 \%$ to $70 \%$ of cases could be prevented by the appropriate consumption of folic acid before conception and during early pregnancy [7]. In 1992, the US Public Health Service recommended that all women capable of becoming pregnant consume $0.4 \mathrm{mg}$ ( or $400 \mu \mathrm{g}$ ) of folic acid daily to reduce their risk for having a pregnancy affected by NTDs [10]. In 1998, the US Food and Drug Administration mandated that folic acid be added to cereal grain products, and a number of media campaigns, health advisory groups [11], and worldwide public health campaigns have been launched to increase the awareness, knowledge, and consumption of folic acid. As a result, the incidence and prevalence of NTDs have declined and stabilized in many countries $[9,12,13,15,20,21,27$, $35,36,42,54]$. While food fortification with folic acid is well established in the USA, Canada, and Chile, in Europe, the discussion, including what is the optimal approach, is still ongoing. Moreover, racial/ethnic disparities and socioeconomic and educational issues in the consumption of folic acid persist, and differences of supplement use by age exist [37]. Therefore, the full potential of folic acid to reduce the risk of NTDs has not yet been realized, and preventable NTDs continue to occur.

Patients with NTDs are at risk of psychosocial problems and have acute, lifelong disabilities, which require a lifetime of medical care $[19,55]$. Cost of illness studies attempts to quantify the economic burden of a disease and estimate all the costs associated with a particular disease. These studies provide information on the economic burden to society or to a specific stakeholder such as the healthcare payer or the patient. Economic evaluation studies evaluate whether the effectiveness or benefit of intervention is worth the cost of implementing the intervention. These studies provide information for decision makers to determine the best way of allocating scarce healthcare resources to ensure a given population receives optimal healthcare.

This paper summarizes the economic evidence from a systematic review that was conducted to understand the humanistic and economic burden of NTDs to healthcare systems, patients, caregivers, and society. While humanistic patient-reported outcome and caregiver burden are focuses of other papers, the objective of this paper is to gain greater insight into the economic burden of NTDs both on healthcare systems and on wider society and to understand the costeffectiveness of folic acid for the prevention of NTDs.

\section{Methods}

A literature review was conducted using a standard systematic approach [14]. To identify relevant studies associated with costs of NTDs and economic evaluations of folic acid for the prevention of NTDs, electronic databases (PUBMED, PsycINFO, and Embase) were searched for material dating from January 1976 to October 2010, using the following search terms:

- Neural tube defects OR NTDs OR spina bifida OR anencephaly OR meningocele AND

- Cost OR economic OR financial burden/impact of illness/ disease OR resource use OR hospitalization OR

- Economic evaluation OR cost analysis OR cost effectiveness OR CEA OR cost minimisation OR CMA OR cost consequence OR CCA OR cost utility OR CUA OR cost benefit OR CBA OR cost savings OR patient preferences AND

- Folic acid OR folate OR vitamin supplements OR food fortifi* OR enriched grain 
The Health Economic Evaluation Database and the Centre for Review and Dissemination databases (NHS Economic Evaluation Database and Health Technology Assessment (HTA)) were also searched in addition to the websites of the major HTA bodies (such as the International Network of Agencies for Health Technology Assessment, National Institute for Health and Clinical Excellence, and Scottish Medicines Consortium in the UK, Institute for Quality and Efficiency in Health Care in Germany, Pharmaceutical Benefits Advisory Committee in Australia, and Canadian Agency for Drugs and Technologies in Health in Canada). The search was limited to English language articles.

Studies identified for inclusion in the review were cost of illness studies reporting resource use and costs associated with NTDs and complications, and economic evaluations estimating both the costs and effects of prevention of NTDs with folic acid. Data were extracted by one researcher using a structured data extraction form and checked by a second researcher. The quality of studies included in the review was assessed using published checklists [17, 39].

All costs have been inflated and converted from local currencies to 2011 Euro $(€)$ using the Consumer Price Index (CPI) inflation calculators (http://www.bls.gov/ data/inflation_calculator.htm, http://www.rba.gov.au/cal culator/annualDecimal.html and http://www.rbnz.govt.nz/ statistics/0135595.html) and currency converter at the exchange rate on 26 April 2011 (i.e. $\$ 1=€ 0.6856$, \$AU1= $€ 0.7363$ and $\$ N Z 1=€ 0.5427$ ) (http://www.foreign-curren cy-uk.com/currency_converter.asp). Actual costs reported in different studies are presented in the brackets. Moreover, the cost per patient was calculated where possible in order to compare the different studies and their varying sample sizes. Where costs have been converted into Euro from other currencies, these costs should only be used as a guide because official exchange rates do not adequately reflect the comparative purchasing power of the local currencies in their own markets [17].

\section{Results}

Literature search results

Fourteen cost of illness studies (12 from the USA, 1 each from Canada and Spain) and 10 economic evaluations on prevention with folic acid ( 4 from the USA, 2 from both Chile and the Netherlands, 1 each from Australia/New Zealand and South Africa) were identified for this review (Fig. 1).

The quality of the cost of illness studies was generally poor. This was largely due to the limited range of costs that were included in these studies and lack of any sensitivity analyses to assess the robustness of results. However,

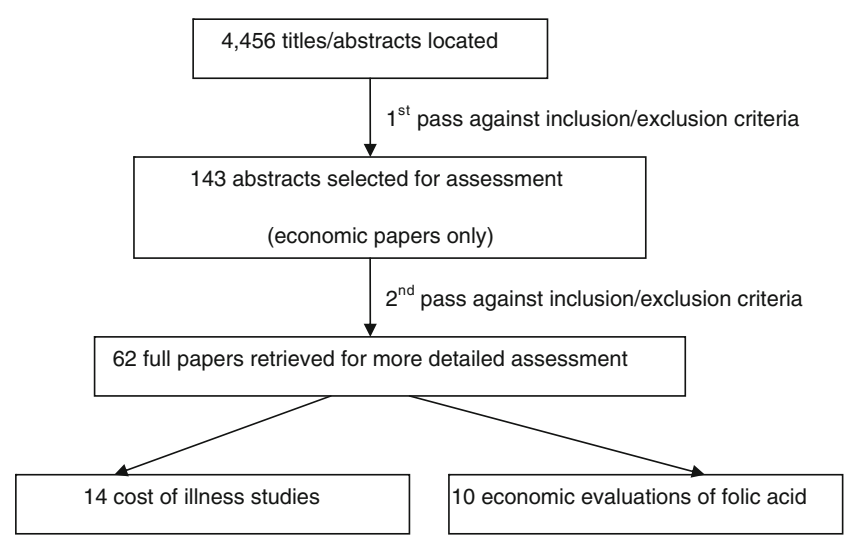

Fig. 1 Selection of the studies reviewed

despite these limitations, the overarching results from these studies are consistent.

Overall, the quality of the economic evaluations was higher. Most of them were carried out using standard and recommended methodology. However, there were wide differences in the way that 'benefits' were measured across the studies such that it was not appropriate to make comparisons between studies.

\section{Economic burden of NTDs}

Table 1 describes the range of costs that were included in each of the cost of illness studies. The majority of studies included the medical costs of NTDs, and seven focused solely on these costs. These are costs that are borne by healthcare payers such as health insurance programmes, and include factors such as drugs and hospitalizations both for managing NTDs directly and for managing comorbidities. The studies by Waitzman et al. [49, 50] are more inclusive and take into account costs associated with development services and special education for individuals living with NTDs. These types of costs are often described as direct nonmedical costs. Broader costs such as lost work time, caregiver costs, and costs due to premature loss of life were considered in the studies by Waitzman et al. [49, 50], Lipscomb et al. [34] and Tilford et al. [47, 48]. These are typically referred to as indirect costs. The study by Young [53] only reported resource use of adult patients with spina bifida in Canada without cost information.

Annual direct medical cost per patient was estimated to be $€ 42,943$ (\$51,574 in 2003\$) for NTD [43] and between $€ 11,728$ (\$11,061 in $1993 \$)$ to $€ 54,270$ (\$65,177 in 2003\$) for spina bifida [28, 40, 43] in the USA. In Spain, the Social Security system spent direct medical costs of $€ 3,825,037$ (\$2,953,138 in 1988\$) per year for the care of patients with spina bifida [3], representing approximately $€ 3,541$ (\$2,734 in $1988 \$)$ per person per year. 
Table 1 Summary of NTD cost of illness studies reviewed (annual cost per patient in 2011€)

\begin{tabular}{|c|c|c|c|c|c|}
\hline References & Country & Direct medical costs & Direct nonmedical costs & Caregiver time costs & Indirect costs \\
\hline $\begin{array}{l}\text { Lipscomb } 1986 \\
\text { [34] }\end{array}$ & USA & - & - & $\begin{array}{l}\text { Average reductions of } 14 \mathrm{~h} \text { per } \\
\text { week in paid work time for } \\
\text { mothers and } 5 \mathrm{~h} \text { per week for } \\
\text { fathers }\end{array}$ & - \\
\hline $\begin{array}{c}\text { Harris et al. } \\
1990 \text { [24] }\end{array}$ & USA & $\begin{array}{l}\text { Skin breakdown in } \\
\text { myeloeningocele: } € 2,466 \\
(1,763 \text { in } 1986 \$)\end{array}$ & - & - & - \\
\hline $\begin{array}{l}\text { Bea et al. } 1994 \\
\text { [3] }\end{array}$ & Spain & $\begin{array}{l}\text { Myeloeningocele: } € 3,541 \\
(2,734 \text { in } 1988 \$)\end{array}$ & - & - & - \\
\hline $\begin{array}{l}\text { Waitzman et al. } \\
1996[50]\end{array}$ & USA & $\begin{array}{l}\text { SB: age } 0-1: € 33,213(34,013 \\
\text { in } 1996 \$) ; \text { age } 2-4: € 14,573 \\
\text { (14,924 in } 1996 \$) \text {; age } 5-17 \text { : } \\
€ 12,897(13,208 \text { in } 1996 \$) ; \\
\text { age } 18+: € 4,095(4,194 \\
\text { in } 1996 \$)\end{array}$ & $\begin{array}{l}\text { SB: total per capita lifetime } \\
\text { cost for development and } \\
\text { special education }\end{array}$ & - & $\begin{array}{l}\text { Average lifetime } \\
\text { cost per case } \\
\text { of SB }\end{array}$ \\
\hline $\begin{array}{l}\text { Kinsman et al. } \\
1996[31]\end{array}$ & USA & $\begin{array}{l}\text { All comorbidity in SB: } € 4,873 \\
\text { (4,462 in } 1992 \$)\end{array}$ & - & - & - \\
\hline $\begin{array}{l}\text { Ireys et al. } 1997 \\
\text { [28] }\end{array}$ & USA & SB: $€ 11,728(11,061$ in $1993 \$)$ & - & - & - \\
\hline $\begin{array}{l}\text { Tilford et al. } \\
2001[48]\end{array}$ & USA & - & - & $\begin{array}{l}\text { Caregiver time costs for a case } \\
\text { of SB: } € 112,901 \text { to } € 135,743 \\
\text { (\$164,675 to } \$ 197,991 \text {, price } \\
\text { year not clear) }\end{array}$ & - \\
\hline $\begin{array}{l}\text { Waitzman et al. } \\
2004[49]\end{array}$ & USA & $\begin{array}{l}\text { Average lifetime cost per case } \\
\text { of SB }\end{array}$ & $\begin{array}{l}\text { Average lifetime cost per case } \\
\text { of SB for development and } \\
\text { special education }\end{array}$ & - & $\begin{array}{l}\text { Average lifetime } \\
\text { cost per case } \\
\text { of SB }\end{array}$ \\
\hline $\begin{array}{l}\text { Ouyang et al. } \\
2007[40]\end{array}$ & USA & SB: $€ 13,248(15,911$ in $2003 \$)$ & - & - & - \\
\hline $\begin{array}{l}\text { Robbins et al. } \\
2007 \text { [43] }\end{array}$ & USA & $\begin{array}{l}\text { NTD: } € 42,943(51,574 \text { in } 2003 \\
\text { \$); SB: €54,270 (65,177 in } \\
\text { 2003\$); Anencephaly: €3,131 } \\
\text { (3,760 in 2003\$); } \\
\text { Encephalocele: } € 37,509 \\
(45,047 \text { in 2003\$) }\end{array}$ & - & - & - \\
\hline $\begin{array}{l}\text { Armour et al. } \\
2009[1]\end{array}$ & USA & $\begin{array}{l}\text { People with SB treated for } \\
\text { urinary tract infection-an } \\
\text { ambulatory care sensitive } \\
\text { condition: average Medical } \\
\text { Care expenditure for } \\
\text { hospitalization } € 8,274 \text { and for } \\
\text { ambulatory care } € 370 \text { (9,300 } \\
\text { and } 416 \text { in } 2000 \$ \text {, } \\
\text { respectively); patient out-of- } \\
\text { pocket for hospitalization } \\
€ 623 \text { and } € 75 \text { for ambulatory } \\
\text { care ( } 700 \text { and } 84 \text { in } 2000 \$ \text {, } \\
\text { respectively) }\end{array}$ & - & - & - \\
\hline $\begin{array}{c}\text { Tilford et al. } \\
2009 \text { [47] }\end{array}$ & USA & - & - & $\begin{array}{l}\text { Caregivers of children with SB } \\
\text { worked an annual average of } \\
7.5 \text { to } 11.3 \mathrm{~h} \text { less per week } \\
\text { depending on the disability } \\
\text { severity. This translated into } \\
\text { lifetime costs of } € 113,910 \\
(133,755 \text { in } 2002 \$) \text { using a } \\
3 \% \text { discount rate and an age- } \\
\text { and sex-adjusted earnings } \\
\text { profile }\end{array}$ & - \\
\hline $\begin{array}{l}\text { Bamer et al. } \\
2010 \text { [2] }\end{array}$ & USA & - & $\begin{array}{l}\text { Average annual Medicaid cost } \\
\text { of AT was } € 347 \text { ( } \$ 494 \text {, price } \\
\text { year not clear) per enrolee } \\
\text { with SB and AT accounted for }\end{array}$ & - & - \\
\hline
\end{tabular}


Table 1 (continued)

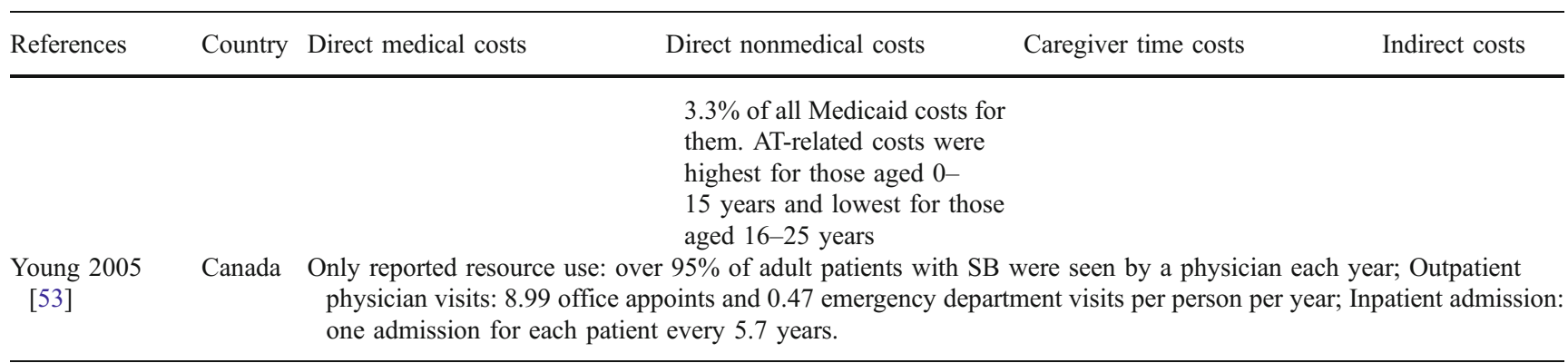

$A T$ assistive technology, $N T D$ neural tube defect, $S B$ spina bifida

A significant proportion of the cost burden occurs during childhood. For example, in the USA, total hospital charges for new born infants with NTDs amounted to $€ 62$ million for spina bifida, $€ 1$ million for anencephaly and $€ 9$ million for encephalocele (\$74 million, \$1 million and \$11 million in 2003\$, respectively) [43]. More specifically, the Medicaid in Washington State spent $€ 2$ million (\$2.1 million in 1993\$) on children with spina bifida in 1993, and average payments for children with spina bifida were 11.6 times higher than the average payment for all children in the state's Medicaid programme [28].

While children and adolescents with spina bifida incur medical expenditures several times higher than children and adolescents without the disease [28,49], young adults with the condition also continue to be high users of medical care [53]. Adults account for $67 \%$ of persons with spina bifida and $66 \%$ of medical expenditures associated with spina bifida in USA [40]. At any age, individuals with spina bifida incur higher medical expenditures than those without, and costs continue to be high throughout adulthood [40] (Fig. 2).

Almost half of the hospital admissions for adults with spina bifida are due to secondary conditions (such as serious urologic infections, renal calculi, pressure ulcers, and osteomyelitis), and the financial costs of these admissions are substantial [31]. The annual direct medical cost per patient for the treatment of spina bifida comorbidities in the USA ranged between $€ 2,466$ [24] and $€ 4,873$
[31]. In Canada, Young [53] reported that hospital admission rate for adults with chronic and complex physical disabilities of childhood including spina bifida is nine times that of the general population, and adult patients with spina bifida are regular users of outpatient and inpatient services (Table 1).

Individuals with spina bifida often require walking aids and wheelchairs for functional mobility. In the USA in any given year, on average, $33 \%$ of individuals with spina bifida made claims from Medicaid for some type of mobility-related assistive technology, including wheelchair-related costs, orthotics and prosthetics, ambulatory aids, and communication and hearing aids [2]. Annually, these claims accounted for $€ 297,704$ (price year not reported), which represents approximately $3.3 \%$ of all reimbursement by Medicaid for all medical care for these individuals [2].

Five studies, which looked beyond the direct costs incurred by the healthcare system when evaluating the burden of NTDs, suggest that indirect costs of spina bifida are substantial. Tilford et al. found [48] a substantial impact of caring for a child with spina bifida on labour force participation, with participation rates $21 \%$ to $27 \%$ lower than those individuals in the control group (population from the Current Population Survey covering the state of Arkansas). Caregivers of children with spina bifida worked an annual average of 7.5 to $11.3 \mathrm{~h}$ less per week depending on disability severity. Differences in work hours by caregivers of children with spina bifida translated into lifetime
Fig. 2 Annual per patient medical expenditures in 2011€: persons with vs. without spina bifida

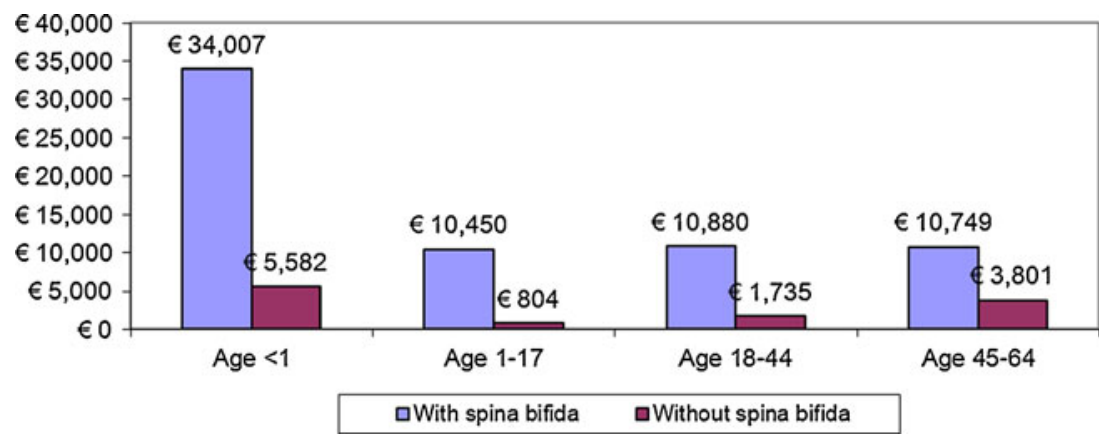

Source: Based on Ouyang et al 2007 [40] 


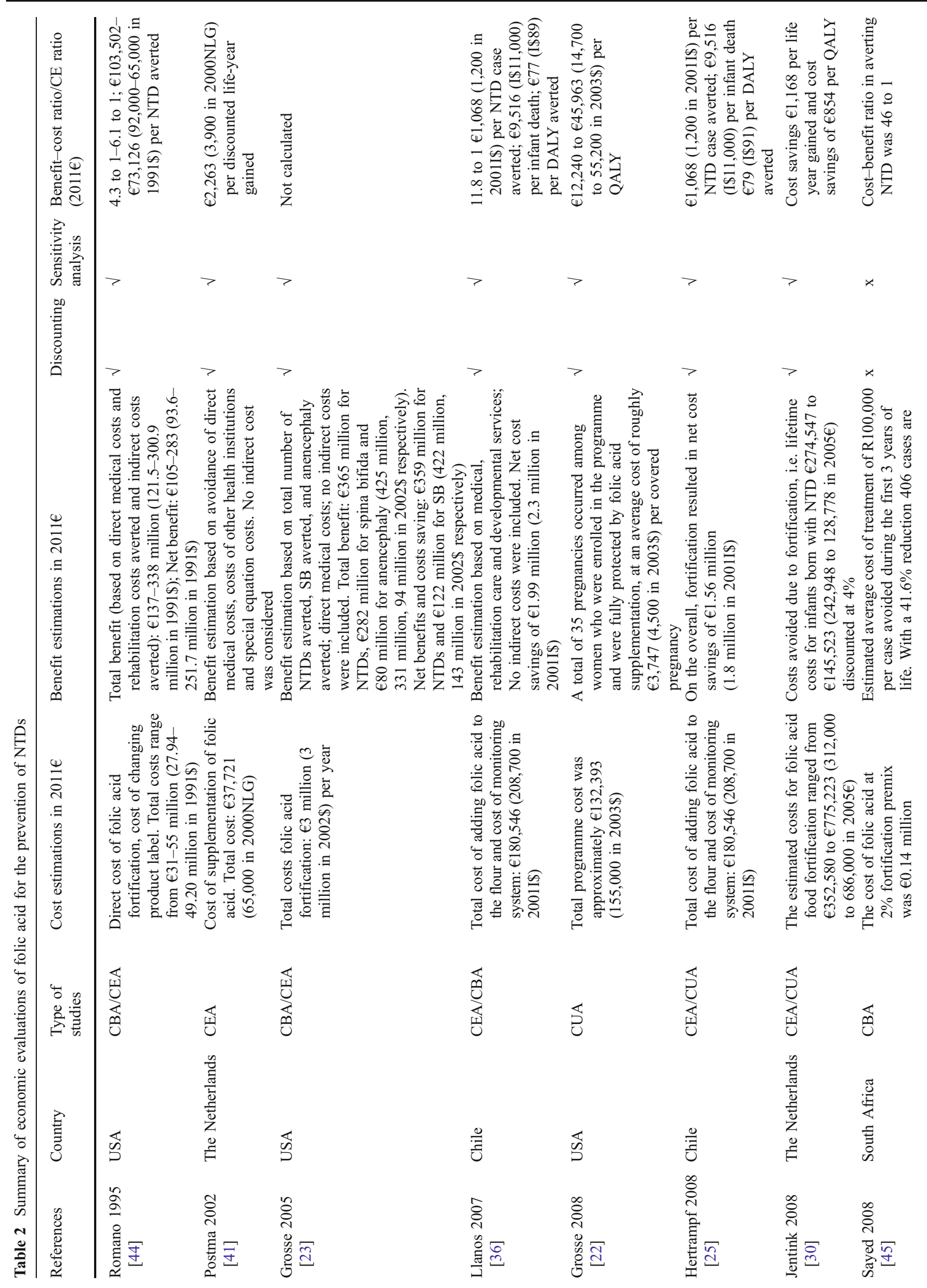



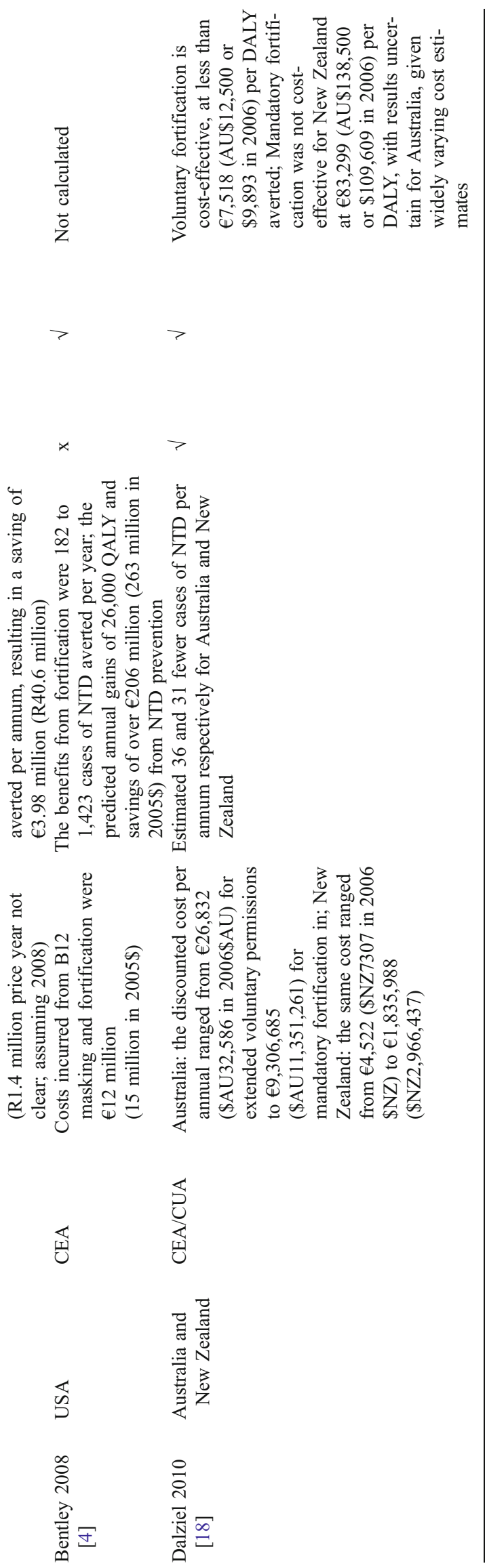

costs of $€ 95,186$ (\$111,755 in 2002\$) using a 3\% discount rate and an age- and sex-adjusted earnings profile. Lipscomb et al. estimated an average reduction of paid work time of $14 \mathrm{~h}$ per week for mothers and $5 \mathrm{~h}$ per week for fathers of children with spina bifida [34]. The estimated caregiver time costs to care for a children with spina bifida until age 25 ranges from $€ 142,477$ to $€ 171,303$ (\$164,675 to $\$ 197,991$ in $2001 \$$ ) depending on the discount rates used in estimating the present value of future costs [47].

Total lifetime costs for patients with spina bifida amounted to $€ 528,425$ (\$620,484 in 2002\$) [50]. Just $37.1 \%$ of the total was attributable to direct medical costs $(€ 187,859$ (\$220,560)), with the costs associated with special education and development services accounting for 6.5\% (€35,204 (\$41,337)) and 0.3\% (€1,732 (\$2,034)), respectively. The remaining $56.1 \%$ of the total were indirect costs $(€ 303,690(\$ 356,553))$, of which $€ 117,613(\$ 138,086)$ were due to increased morbidity and $€ 186,085(\$ 218,477)$ due to premature mortality [50].

Economic impact of preventing NTDs with folic acid

Although there is a limited research in this field, the available evidence indicates that the economic burden of NTDs is substantial. A reduction in the incidence and prevalence of NTDs would reduce this economic burden. Very few studies have evaluated the cost-effectiveness of prevention strategies for NTDs. In the 10 identified economic evaluation studies of folic acid for the prevention of NTDs, 8 evaluated the cost-effectiveness of folic acid fortification in foods [4, 18, 23, 25, 30, 36, 44, 45], and 2 evaluated the cost-effectiveness of periconceptional supplementation of folic acid [22, 41] (Table 2). Nine of the studies included direct medical costs only; indirect costs and benefits were included in only one study [44].

While it is inappropriate to compare results across the identified studies due to the differences in the measures of benefits, each individual study suggested that prevention with folic acid is cost-effective, i.e. that the benefits outweighed the cost (except for mandatory fortification for New Zealand).

In the eight economic evaluations on folic acid food fortification identified by this literature review, all concluded that fortification of food with folic acid is a cost-effective method for reducing the incidence of NTDs. As shown in Table 2, the benefit-cost ratio, a measure of cost-benefit, ranged from 4.3 to 1 in USA [44], 11.8 to 1 in Chile [25, 36] to 30 to 1 in South Africa [45], suggesting that the economic benefit from the prevention of NTDs greatly exceeded the cost of folic acid fortification in these countries. The cost per NTD averted, a measure of cost-effectiveness, was estimated to range from $€ 1,068$ in Chile $[25,36]$ to $€ 103,502$ (\$65,000 to $\$ 92,000$ in $1991 \$$ ) in the USA [44]. The cost savings 
per life year gained was estimated to be $€ 1,168$ in the Netherlands [30]. The cost per disability-adjusted quality of life (DALY) averted was estimated to be close to $€ 80$ in Chile $[25,36]$ and $€ 7,518$ for voluntary fortification in Australia and New Zealand. The cost per quality-adjusted life year (QALY), a measure of cost-utility, was estimated to be $€ 854$ in the Netherlands [30].

Similarly, economic evaluations suggest that periconceptional supplementation of folic acid is a good use of healthcare resources and justifies further promotion of the use of folic acid supplementation prior to pregnancy. The cost per life year gained from periconceptional supplementation of folic acid was estimated to be $€ 2,108$ (NLG 3,900 in 2000 price) in the Netherlands [41]. In the USA, the cost per QALY gained from the NTD recurrence prevention programmes promoting folic acid supplementation ranged from $€ 12,240$ to $€ 45,963$ ( $\$ 14,700$ to $\$ 55,200$ in $2003 \$$ ), which led the authors to conclude that the NTD recurrence prevention programme provided value for the money spent relative to other public health interventions [22].

In all the countries where cost-benefit of folic acid for the prevention of NTDs was evaluated, several millions to hundreds of millions of Euros (or dollars) of net benefit or cost savings were estimated. These results strongly support the continuation of folic acid for the prevention of NTDs, especially in countries with NTD prevalence far above the observed floor for folic acid-preventable NTD [26].

\section{Discussion}

There are some limitations to this review which deserve comment. Given the gravity of NTDs, we found surprisingly few studies that evaluated the economic burden of the disease and the economic impact of prevention with folic acid. These studies reported findings from a limited number of countries (mainly the USA) and focused on spina bifida over other NTDs. In addition, most of the studies were based on data collected more than 10 years ago and therefore may not reflect techniques currently used for prenatal diagnosis and interruption of pregnancy and management of NTDs [8]. The quality of the cost of illness studies was generally poor, with few studies addressing all important aspects of cost of illness and uncertainties around the estimation of costs. Methodological differences limited comparisons between studies. Moreover, while the economic evaluations were of good quality, comparisons between studies could not be made because the measures of benefit differed.

Despite these limitations, consistent findings were reported across all studies. NTDs represent a high cost per patient to healthcare payer and society. Key cost drivers are the inpatient days at initial diagnosis in childhood and, later in life, treatment of comorbidities in survivors. The lifetime costs are significant, as patients require ongoing care throughout their lives. Patients with NTDs also require other forms of support that result in direct nonmedical costs, such as special education, developmental services and mobility-related assistive devices. Caregivers of children with spina bifida are impacted by economic factors such as a reduction of paid work time. In addition, there are significant indirect costs associated with NTDs due to the reduced productivity of the patients themselves. These results demonstrate the significant lifetime cost burden of NTDs to healthcare systems, various healthcare payers, caregivers, and society in general.

As caregiver time costs and indirect costs associated with morbidity and premature death of individuals with NTDs are significant, they should be included in economic evaluations of interventions to prevent NTDs. However, a few of the available economic evaluations of folic acid have considered caregiver time costs and indirect costs. The review found that even without considering the significant indirect costs associated with NTDs, folic acid fortification in food and preconception folic acid consumption are still costeffective ways to reduce the incidence and prevalence of NTDs. However, the full potential of folic acid to reduce the risk of NTDs has not been realized in many countries, suggesting that more can be done to reduce greatly the incidence of the condition and its associated economic burden.

Further research is required to understand fully the economic impact of NTDs. Studies in a wider range of countries are needed, as differences in the healthcare system structure and in the management of NTDs across countries limit the generalizability of the findings from the studies reported here to other countries. In order to understand fully the burden of this disease, a broader range of costs should be measured. Outpatient care costs and broader societal costs such as nonmedical costs and the indirect costs associated with lost productivity and premature death would be of particular interest, given the limited data currently available. Moreover, in order to compare the cost-effectiveness of alternative prevention strategies, future studies should use a standard approach to the measurement of effectiveness or benefit of the prevention strategies. The use of a generic measure of benefit, for example quality-adjusted life years saved, would enable those who fund healthcare for a defined population to assess the value of alternative prevention options for NTDs and therefore fund the option that provides the maximal benefit within the funds available.

\section{Conclusion}

This review has highlighted the significant cost burden that NTDs pose to healthcare systems, various healthcare payers, and wider society, concluding that the benefits of 
preventing this condition with folic acid outweigh the costs of such initiatives. In countries where the full potential of folic acid to reduce the risk of NTDs has not been realized, further intervention with folic acid is justified.

Acknowledgements We thank Dr Diana Rofail at Mapi Values who had been highly involved throughout the design of study and implementation of the review, interpretation of the results, and development of the report. Bayer Healthcare has commissioned Mapi Values to conduct a systematic literature review on humanistic and economic impact of NTDs. The preparation of this manuscript was based on the systematic review results and was conducted in collaboration between Mapi Values and Bayer Health Economics and Outcomes Research team by the authors listed.

Open Access This article is distributed under the terms of the Creative Commons Attribution Noncommercial License which permits any noncommercial use, distribution, and reproduction in any medium, provided the original author(s) and source are credited.

\section{References}

1. Armour BS, Ouyang L, Thibadeau J, Grosse SD, Campbell VA, Joseph D (2009) Hospitalization for urinary tract infections and the quality of preventive health care received by people with spina bifida. Disabil Health J 2:145-152

2. Bamer AM, Connell FA, Dudgeon BJ, Johnson KL (2010) Frequency of purchase and associated costs of assistive technology for Washington State Medicaid program enrollees with spina bifida by age. Disabil Health J 3:155-161

3. Bea M, Diaz LI, Martinez A, Lopez A, Garcia AV, Forner V (1994) A multicentre study of the hospital care of 1500 patients with myelomeningocele. Paraplegia 32:561-564

4. Bentley TG, Weinstein MC, Willett WC, Kuntz KM (2008) A cost-effectiveness analysis of folic acid fortification policy in the US. Public Health Nutr 12:455-467

5. Berry RJ, Li Z, Erickson JD, Li S, Moore CA, Wang H et al (1999) Prevention of neural-tube defects with folic acid in China. China-US Collaborative Project for Neural Tube Defect Prevention. N Engl J Med 341:1485-1490

6. Blencowe H, Cousens S, Modell B, Lawn J (2010) Folic acid to reduce neonatal mortality from neural tube disorders. Int $\mathrm{J}$ Epidemiol 39:i110-i121

7. Botto LD, Moore CA, Khoury MJ, Erickson JD (1999) Neural-tube defects. N Engl J Med 341:1509-1519

8. Case AP, Canfield MA (2009) Methods for developing useful estimation of the costs associated with birth defects. Birth Defects Res A Clin Mol Teratol 85:920-924

9. Castilla E, Orioli I, Lopez C, Dutra M, Nazer H (2003) Preliminary data on changes in neural tube defect prevalence rates after folic acid fortification in South America. Am J Med Genet A 123:123-128

10. Centers for Disease Control and Prevention (1992) Recommendations for the use of folic acid to reduce the number of cases of spina bifida and other neural tube defects. MMWR 41:1-7

11. Centers for Disease Control and Prevention (1999) Annex A: fact sheets for candidates diseases for elimination or eradication. MMWR Supplements 48(SU01):154-203

12. Centers for Disease Control and Prevention (2004) Spina bifida and anencephaly before and after folic acid mandate-United States, 1995-1996 and 1999-2000. MMWR 53:362-365

13. Centers for Disease Control and Prevention (2008) Use of supplements containing folic acid among women of childbearing age-United States. MMWR 57(1):5-8
14. Centre for Reviews and Dissemination (2009) Systematic reviews: CRD's guidance for undertaking reviews in health care. http:// www.york.ac.uk/inst/crd/SysRev/!SSL!/WebHelp/SysRev3.htm. Accessed 27 Apr 2011

15. Chen L, Rivera M (2004) The Costa Rican experience: reduction of neural tube defects following food fortification programs. Nutr Rev 62:S40-S43

16. Christianson A, Howson CP, Modell B (2006) March of Dimes global report on birth defects: the hidden toll of dying and disabled children. http://www.marchofdimes.com/downloads/ Birth_Defects_Report-PF.pdf. Accessed 27 Apr 2011

17. Cooper NJ (2000) Economic burden of rheumatoid arthritis: a systematic review. Rheumatology 39:28-33

18. Dalziel KS, Segal L, Katz R (2010) Cost-effectiveness of mandatory folate fortification $v$. other options for the prevention of neural tube defects: results from Australia and New Zealand. Public Health Nutr 13:566-578

19. Date I, Yagyu Y, Asari S, Ohmoto T (1993) Long-term outcome in surgically treated spina bifida cystica. Surg Neurol 40:471-475

20. De Wals P, Tairou F, Van A, Uh S, Lowry R, Sibbald B et al (2007) Reduction in neural-tube defects after folic acid fortification in Canada. N Engl J Med 357:135-142

21. Grace HJ (1981) Prenatal screening for neural tube defects in South Africa An assessment. S Afr Med J 60:324-329

22. Grosse SD, Ouyang L, Collins JS et al (2008) Economic evaluation of a neural tube defect recurrence-prevention program. Am J Prev Med 35:572-577

23. Grosse SD, Waitzman NJ, Romano PS, Mulinare J (2005) Reevaluating the benefits of folic acid fortification in the United States: economic analysis, regulation, and public health. Am J Public Health 95:1917-1922

24. Harris MB, Banta JV (1990) Cost of skin care in the myelomeningocele population. J Pediatr Orthop 10:355-361

25. Hertrampf E, Cortes F (2008) National food-fortification program with folic acid in Chile. Food Nutr Bull 29:S231-S237

26. Heseker HB, Mason JB, Selhub J, Rosenberg IH, Jacques PF (2009) Not all cases of neural-tube defect can be prevented by increasing the intake of folic acid. Br J Nutr 102:173-180

27. Honein MA, Paulozzi LJ, Mathews TJ, Erickson JD, Wong LY (2001) Impact of folic acid fortification of the US food supply on the occurrence of neural tube defects. JAMA 285:29812986

28. Ireys HT, Anderson GF, Shaffer TJ, Neff JM (1997) Expenditures for care of children with chronic illnesses enrolled in the Washington State Medicaid program, fiscal year 1993. Pediatrics 100:197-204

29. Jaquier M, Klein A, Boltshauser E (2006) Spontaneous pregnancy outcome after prenatal diagnosis of anencephaly. BJOG 113:951-953

30. Jentink J, van de Vrie-Hoekstra NW, de Jong-van den Berg LT, Postma MJ (2008) Economic evaluation of folic acid food fortification in the Netherlands. Eur J Public Health 18:270274

31. Kinsman SL, Doehring MC (1996) The cost of preventable conditions in adults with spina bifida. Eur J Pediatr Surg 6:17-20

32. Landon J, Thorpe L (1998) Changing preconceptions: volume 1: the HEA folic acid campaign 1995-1998: summary report.

33. Leask K (2011) NHS Evidence-genetic conditions: neural tube defects. http://www.library.nhs.uk/geneticconditions/viewresource. aspx?resID=93936 Accessed 27 Apr 2011

34. Lipscomb J (1986) Human capital, willingness-to-pay and costeffectiveness analyses of screening for birth defects in North Carolina. Duke University, Durham

35. Liu S, West R, Randell E, Longerich L, Connor KS, Scott H et al (2004) A comprehensive evaluation of food fortification with folic acid for the primary prevention of neural tube defects. BMC Pregnancy Childbirth 4:10 
36. Llanos A, Hertrampf E, Cortes F, Pardo A, Grosse SD, Uauy R (2007) Cost-effectiveness of a folic acid fortification program in Chile. Health Policy 83:295-303

37. National Health and Medical Research Council (1993) Revised statement on the relationship between dietary folic acid and neural tube defects such as spina bifida. 15th Session of the National Health and Medical Research Council, Australia

38. Mosley B, Hobbs C, Flowers B, Smith V, Robbins J (2007) Folic acid and the decline in neural tube defects in Arkansas. J Ark Med Soc 103:247-250

39. NICE (2009) Methods for development of NICE public health guidance (second edition). http://www.nice.org.uk/media/CE1/F7/ CPHE_Methods_manual_LR.pdf. Accessed 27 Apr 2011

40. Ouyang LJ, Grosse SD, Armour BS, Waitzman NJ (2007) Health care expenditures of children and adults with spina bifida in a privately insured US population. Birth Defects Res A Clin Mol Teratol 79:552-558

41. Postma MJ, Londeman J, Veenstra M, De Walle HEK, de Jong van den Berg LTW (2002) Cost-effectiveness of periconceptional supplementation of folic acid. Pharm World Sci 24:8-11

42. Ray J, Meier C, Vermeulen M, Boss S, Wyatt P, Cole D (2002) Association of neural tube defects and folic acid food fortification in Canada. Lancet 360:2047-2048

43. Robbins JM, Bird TM, Tilford JM et al (2007) Hospital stays, hospital charges, and in-hospital deaths among infants with selected birth defects: United States, 2003. MMWR 56(2):25-29

44. Romano PS, Waitzman NJ, Scheffler RM, Pi RD (1995) Folic acid fortification of grain: an economic analysis. Am J Publ Health 85:667-676

45. Sayed AR, Bourne D, Pattinson R, Nixon J, Henderson B (2008) Decline in the prevalence of neural tube defects following folic acid fortification and its cost-benefit in South Africa. Birth Defects Res A Clin Mol Teratol 82:211-216
46. Scofield JC, Campbell PR (2001) Integrating the spina bifida patient into the general dental practice. The Journal of Practical Hygiene. May and June 27-31

47. Tilford JM, Grosse SD, Goodman AC, Li K (2009) Labor market productivity costs for caregivers of children with spina bifida: a population-based analysis. Med Decis Mak 29:23-32

48. Tilford JM, Robbins JM, Hobbs CA (2001) Improving estimates of caregiver time cost and family impact associated with birth defects. Teratology 64:S37-S41

49. Waitzman, NJ, Romano, PS, Grosse, SD (2004) The half-life of cost-of-illness estimates: the case of spina bifida. Working Paper No: 2004-07. Department of Economics, University of Utah

50. Waitzman NJ, Scheffler RM, Romano PS (1996) The cost of birth defects: estimates of the value of prevention. University Press of America, Lanham

51. Williams P, Williams A, Graff J, Hanson S, Stanton A, Hafeman C et al (2002) Interrelationships among variables affecting well siblings and mothers in families of children with a chronic illness or disability. J Behav Med 25:411-424

52. Wolff T, Witkop CT, Miller T, Syed S (2009) Folic acid supplementation for the prevention of neural tube defects: an update of the evidence for the US preventive services task force. Ann Intern Med 150:632-639

53. Young N, Steele C, Fehlings D, Jutai J, Olmsted N, Williams J, Williams JI (2005) Use of health care among adults with chronic and complex physical disabilities of childhood. Disabil Rehabil 27:1455-1460

54. Zlotogora J, Amitai Y, Leventhal A (2006) Surveillance of neural tube defects in Israel: the effect of the recommendation for periconceptional folic acid. Isr Med Assoc J 8:601-604

55. Zurmohle UM, Homann T, Schroeter C, Rothgerber H, Hommel G, Ermert J (1998) Psychosocial adjustment of children with spina bifida. J Child Neurol 13:64-70 